\section{Espacio urbano, guerra y enfermedades sociales: el caso del tracoma infantil en Valencia, 1936-1937}

\section{Urban space, war and social diseases: the case of infantile trachoma in Valencia, 1936-1937}

\section{Xavier García Ferrandis $s^{i}$}

i Profesor, Departamento de Medicina Social y Salud Pública/ Universidad Católica de Valencia San Vicente Mártir. Valencia - País Valenciano - España orcid.org/0000-0002-0575-6902 xavier.garcia@ucv.es
GARCÍA FERRANDIS, Xavier. Espacio urbano, guerra y enfermedades sociales: el caso del tracoma infantil en Valencia, 1936-1937. História, Ciências, Saúde Manguinhos, Rio de Janeiro, v.28, n.4, out.-dez. 2021, p.1037-1058.

\section{Resumen}

Desde finales de 1937 tuvo lugar en España un repunte de enfermedades endémicas, como el tracoma. Esta enfermedad había sido controlada desde comienzos del siglo XX, especialmente durante la Segunda República (19311936); sin embargo, la degradación de las condiciones de vida y los movimientos de población durante la Guerra Civil española (1936-1939) facilitaron la recrudescencia de la endemia tracomatosa. El objetivo de este artículo es analizar las consecuencias que tuvo la Guerra Civil en la organización de la lucha contra el tracoma infantil en Valencia, una ciudad en la retaguardia republicana donde pronto apareció la miseria y el hacinamiento, escenario ideal para la irrupción del tracoma.

Palabras clave: Guerra Civil española (1936-1939); tracoma infantil; ciudad de Valencia; niños refugiados; hospital.

\section{Abstract}

From late 1937 on, there was a resurgence in Spain of endemic diseases such as trachoma. This disease had been controlled since the beginning of the twentieth century, especially during the Second Republic (1931-1936); however, the decline in living conditions and the population displacements during the Spanish Civil War (1936-1939) facilitated the resurgence of endemic trachoma. This article seeks to analyze the consequences of the Civil War on the struggle against infantile trachoma in Valencia, a city in the rearguard of the Republican zone in which poverty and overcrowding appeared suddenly, an ideal scenario for an outbreak of trachoma.

Keywords: Spanish Civil War (1936-1939); infantile trachoma; city of Valencia; refugee children; hospital. 
$\mathrm{C}$ omo es conocido, los higienistas de la Europa del tránsito del siglo XIX al XX defendían que las enfermedades infecciosas no podían ser abordadas en exclusividad desde la doctrina bacteriológica, sino que, además, se debía tener en cuenta las circunstancias socioeconómicas de los grupos humanos que las padecían. La miseria, la desnutrición, el hacinamiento, la vivienda insalubre, entre otros, eran factores que se asociaban a las enfermedades que producían las mayores tasas de mortalidad, como la tuberculosis. En este contexto surgió el concepto de "enfermedad social" asociado a la desigualdad humana que había provocado la industrialización del mundo occidental (Molero Mesa, 2006). Uno de los elementos característicos de la medicina es la capacidad de intervenir directamente en el medio social y familiar a través de las campañas sanitarias que fueron incorporadas a la política sanitaria de los países industrializados a lo largo de la primera mitad del siglo XX (Medina, Rodríguez-Ocaña, 1994; Arrizabalaga, Martínez-Vidal, Pardo Tomás, 1998).

En este trabajo seguimos la acepción del término enfermedad social recogido por Rodríguez-Ocaña y Molero. Estos autores destacan que posiblemente las tres campañas médico-sociales más relevantes en el mundo industrializado fueron las diseñadas contra la tuberculosis (considerada por Molero como la enfermedad social por excelencia), la sífilis y la mortalidad infantil; en algunos países mediterráneos, también adquirieron gran importancia las campañas antipalúdicas y contra el tracoma (Molero Mesa, 1989; 1994; 2006; Rodríguez-Ocaña et al., 2003; García Ferrandis, 2013). Y, en la España de la posguerra inmediata, fue especialmente destacable la lucha contra el tifus exantemático (Jiménez Lucena, 1994; García Ferrandis, Martínez-Vidal, 2019).

En cuanto a la historiografía sobre el tracoma, el carácter crónico de la enfermedad y el hecho de aparecer sus secuelas en la edad adulta explicarían que se haya prestado menos atención al tracoma como enfermedad infantil. Sin embargo, la mayoría de las primoinfecciones tracomatosas aparecían en la primera infancia y en la edad escolar, lo que tenía una gran importancia social, epidemiológica y terapéutica. La historiografía española ha abordado la importancia de las enfermeras visitadoras (Galiana-Sánchez, BernabeuMestre, 2011), el papel que desempeñaron los factores medioambientales en el desarrollo de la endemia en la España contemporánea), la articulación de la lucha contra la enfermedad en España entre 1920 y 1930 (Galiana-Sánchez, Cremades Monerris, Bernabeu-Mestre, 2010), así como la epidemiología del tracoma entendido como enfermedad asociada a la miseria (Bernabeu-Mestre, Galiana-Sánchez, Monerris, 2013).

En el plano internacional destacan los trabajos de Lucia Pozzi, que desde hace años investiga la presencia del tracoma en Italia durante la primera mitad del siglo XX y, en algunas publicaciones, también en España (Melis, Pozzi, 2013; Pozzi, Galiana-Sánchez, Bernabeu-Mestre, 2015; Pozzi, Bernabeu-Mestre, Galiana-Sánchez, 2017).

En el ámbito valenciano destaca el trabajo de Carmen Barona, que aborda la lucha antitracomatosa durante el primer tercio del siglo XX, pero sin adentrarse en la convulsa etapa correspondiente a la Guerra Civil (Barona Vilar, 2006). Si acaso, se ha abordado de forma tangencial (García Ferrandis, 2015; García Ferrandis, Martínez-Vidal, 2016a), pese a constituir un período fundamental en el estudio de las enfermedades sociales debido a 
que durante la contienda se generó una dinámica social basada en grandes movimientos de población infantil desde las zonas de conflicto a la retaguardia. Estos contingentes a menudo sufrieron la falta de viviendas y de infraestructuras sanitarias en las ciudades de acogida, lo que pronto se tradujo en hacinamiento que, junto a la malnutrición, acabaría por provocar serios problemas de salud pública en diferentes escenarios de la ciudad de Valencia. ${ }^{1}$ Nuestra hipótesis es que dado que el hacinamiento y la malnutrición están íntimamente relacionadas con la epidemiología del tracoma, resulta plausible plantearse que durante la Guerra Civil se produjo en Valencia una recrudescencia de la tradicional endemia de tracoma infantil. El curso desfavorable de la guerra para el bando republicano explicaría que aquellos factores epidemiológicos aparecieran con más intensidad en los principales bastiones de la retaguardia republicana, como Valencia. Asimismo, se pretende analizar cómo se articuló la lucha contra la enfermedad en la ciudad. ${ }^{2}$

Pese a la proyección local de este trabajo, conviene recordar que este tipo de estudios son fundamentales en el abordaje de lo que aconteció durante la guerra en la España republicana, debido a las diversas realidades que se vivieron en esta zona provocadas por la desintegración del Estado y la atomización del poder (Gómez Bravo, 2012; 2016). El caso valenciano resulta especialmente importante dado que la ciudad estuvo situada en la retaguardia durante la totalidad de la guerra, con las consecuencias demográficas, sociales y sanitarias que ello supuso.

Finalmente, cabe destacar que esta investigación supone una aportación a la historiografía de la medicina durante de Guerra Civil española, unas contribuciones que, como es bien sabido, son limitadas. Además, este trabajo se engloba en una línea de investigación internacional que aborda la medicina en tiempos de guerra (Cooter, Harrison, Sturdy, 1999; Marqués, 2000; Coni, 2007; Willis, 2008; Palfreeman, 2015; Steinacher, 2017; Browne, 2018).

Para alcanzar los objetivos propuestos y contrastar así la hipótesis planteada analizaremos documentos de archivo, principalmente los custodiados en el Archivo General y Fotográfico de la Diputación de Valencia. Además, se han consultado varias fuentes médicas de la época; en el ámbito internacional, hemos explorado las actas del Concilium Ophtalmologicum: Organisation internationale de la lutte contre le trachome, congreso que se celebró en Madrid en 1933; en el ámbito español hemos revisado la Revista de Sanidad e Higiene Pública y Semana Médica Española: Revista Técnica y Profesional de las Ciencias Médicas; finalmente, las revistas valencianas que se han analizado han sido Crónica Médica y el Boletín del Instituto Provincial de Higiene de Valencia.

Otras fuentes impresas consultadas han sido las memorias e informes que editaron los organismos oficiales republicanos, tanto en la etapa pre-bélica como durante la guerra, con el fin de visibilizar los logros conseguidos en materia de salud pública en general y en el ámbito antitracomatoso en particular. Fueron consultadas en el Pavelló de la República (Universitat de Barcelona) y en la Facultad de Medicina de la Universidad Complutense de Madrid. Estas publicaciones han sido revisadas con cierta cautela dado que tienen un límite: su posible carácter propagandístico. Finalmente, se han utilizado fuentes iconográficas, entre las que destaca un cartel de la Guerra Civil, editado en Valencia, que denuncia el origen social del tracoma. 


\section{La lucha antitracomatosa en España durante el primer tercio del siglo XX}

Tradicionalmente el tracoma había presentado un carácter endémico en la costa mediterránea. Durante la época de la dictadura Primo de Rivera se impulsó la construcción de los primeros dispensarios antitracomatosos. Sin embargo, en el caso de Valencia, en 1926, el "Informe sobre la sanidad española", del salubrista norteamericano Charles A. Bailey, ponía de manifiesto la ausencia de un dispensario de estas características en la ciudad y cuestionaba la efectividad de la campaña antitracomatosa, ya que "los problemas de esta provincia son fiebre tifoidea, de malta, tracoma, paludismo y lepra, contra ninguno de los cuales se combate" (citado en Rodríguez Ocaña, 2001, p.78-79).

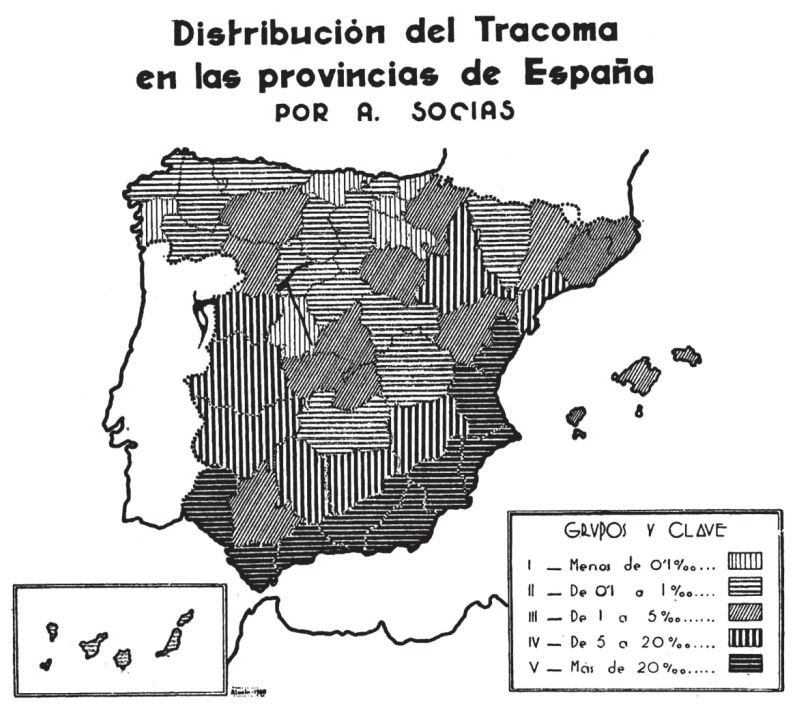

Figura 1: Endemia tracomatosa en la costa mediterránea durante el primer tercio del siglo XX (Socías, 1942, p.377)

Durante la Segunda República, la lucha contra el tracoma constituyó una prioridad para la Dirección General de Sanidad. Así, en 1932, el presupuesto para la lucha antitracomatosa se incrementó notablemente, lo que permitió la construcción de diez "Servicios Centrales Especializados", provistos de material quirúrgico completo y dirigidos por médicos oculistas de reconocida competencia (DGS, 1933, p.7). Entre las funciones de estos centros estaba el abordaje quirúrgico del tracoma y la formación de médicos en la prevención y el tratamiento de la enfermedad. Asimismo, se contaba con 48 "servicios locales" repartidos en las provincias endémicas y dependientes de los respectivos institutos provinciales de higiene. Además de la asistencia no quirúrgica, estos dispensarios tenían como objetivo la estadística y la propaganda sanitaria - tal y como se denominaba la educación sanitaria en la época - así como la investigación etiológica. En la provincia de Valencia existían cuatro de estos dispensarios situados en Alzira, Sueca, Gandia y Carlet, además del Servicio Central Especializado, establecido en Sagunt. Al frente del de Sueca estaba el oftalmólogo y político valenciano Lorenzo Rubio Huerta (1885-1947) quien, además de destacar el origen 
social del tracoma, insistía en la importancia de la escuela en la lucha contra la enfermedad (Rubio Huerta, 1933). ${ }^{3}$

La Dirección General de Sanidad era plenamente consciente del origen social de la enfermedad: "Lo que pudiéramos llamar ambiente tracomatoso es un medio pobre, sucio, polvoriento, con chozas, cuevas o cabañas, en donde personas y animales viven hacinados". Y se hacía un llamamiento a los poderes públicos, "ya que la difusión de la cultura e higiene y el mejoramiento progresivo de las condiciones de vivienda, alimentación y trabajo de las clases proletarias son los medios más poderosos de acabar con esta plaga social" (DGS, 1933, p.10).

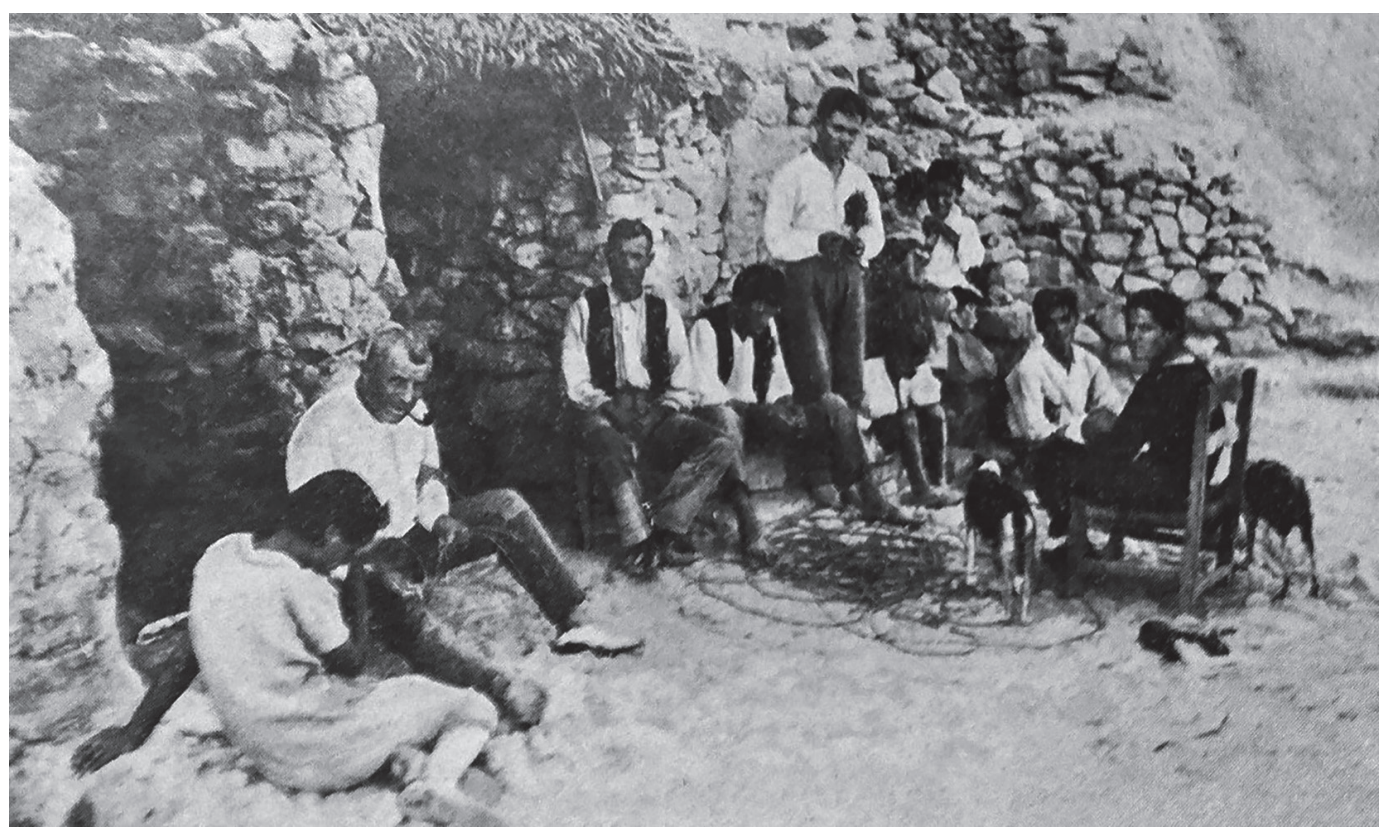

Figura 2: Cuevas habitadas en Lorca, Murcia4 (DGS, 1933, p.7)

En 1933, con motivo del segundo aniversario de la proclamación de la República, la Dirección General de Sanidad publicó un segundo folleto en el que se daba buena cuenta de las principales infraestructuras sanitarias habilitadas de nueva planta o financiadas por la República hasta el momento (DGS, 14 abr. 1933). Pese a ser un material muy valioso - está profusamente ilustrado -, se advierte un carácter menos técnico y más propagandístico que la Memoria del Servicio Antitracomatoso. Además, respecto a la lucha antitracomatosa en la provincia de Valencia, no aporta ninguna novedad.

Como ya se ha mencionado, entre el 16 y el 22 de abril de 1933 se celebró en Madrid el $14^{\circ}$ Concilium Ophtalmologicum, órgano de la organización internacional de la lucha contra el tracoma. Ramón Álvarez Torres, secretario de la Comisión Central de lucha contra el tracoma, presentó una comunicación titulada "Estado actual de la lucha contra el tracoma en España" (Concilium..., 1933). En realidad se trata de una adaptación de la Memoria del Servicio Antitracomatoso, que él mismo había redactado. El objetivo era informar a los expertos internacionales de los avances de España en materia antitracomatosa. La ponencia 
destacaba la importancia de la estadística sanitaria proponiendo una ficha a tal efecto. Por otra parte, en 1934 el Servicio Antitracomatoso editó una cartilla para la prevención individual de la enfermedad (DGS, 1934).

A través de todas estas iniciativas hemos podido apreciar como durante el período republicano prebélico la lucha antitracomatosa se benefició de un fuerte impulso. ${ }^{5}$ De gran importancia resultó el seguimiento especial de la población escolar para detectar casos precoces de la enfermedad. Este segmento poblacional preocupaba especialmente a los higienistas, ya que los escolares eran muy susceptibles a contraer la conjuntivitis tracomatosa por las deficientes condiciones higiénicas de las escuelas. Por este motivo, se instruyó a los maestros en normas básicas para evitar el contagio de la enfermedad; por ejemplo, la separación de los escolares enfermos de los sanos (Barona Vilar, 2006). Además de centrarse en el ámbito escolar, conviene destacar que en España las campañas contra el tracoma desarrolladas durante el primer tercio del siglo XX se articularon alrededor de la figura de la enfermera visitadora, especialmente durante la Segunda República (GalianaSánchez, Bernabeu-Mestre, 2011).

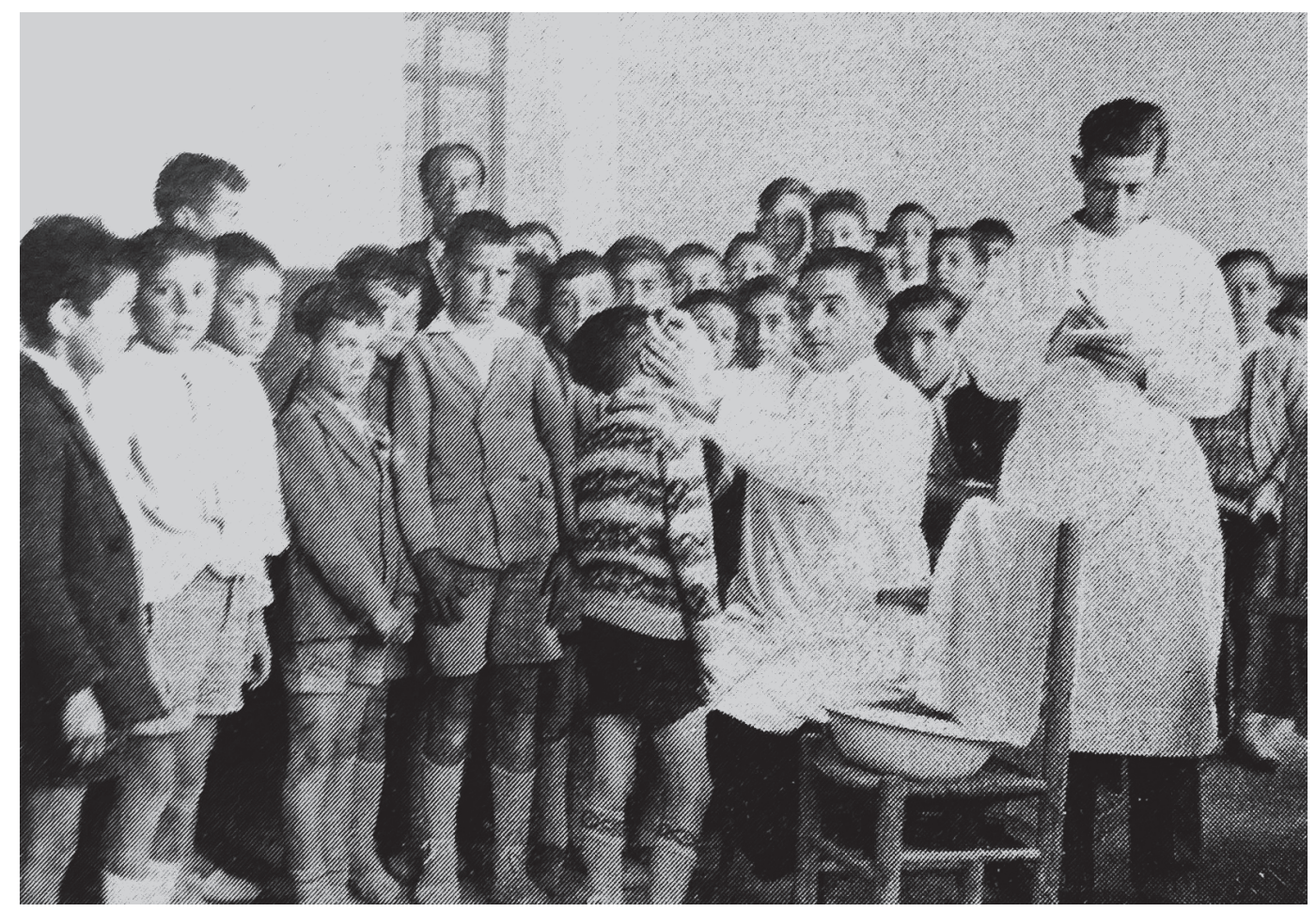

Figura 3: Inspección ocular en Cieza, Murcia (DGS, 1933, p.7)

Los esfuerzos de las autoridades sanitarias republicanas en materia antitracomatosa dieron sus frutos y, en 1935, los casos complicados con retracciones cicatriciales se redujeron a la mitad respecto de años anteriores. El número más elevado de casos pasó a corresponderse con formas crónicas de tracoma sin complicaciones y con formas incipientes y dudosas (Álvarez, 1936). 
Además de los dispensarios antitracomatosos de la provincia de Valencia que hemos mencionado anteriormente, en 1933 la sección de bacteriología del Instituto Provincial de Higiene de Valencia puso en marcha una línea de investigación sobre la etiopatogenia y la bacteriología del tracoma. Para ello se utilizó material biológico procedente de los dispensarios provinciales (exudados conjuntivales, productos de raspado etc.). Sin embargo, dada la magnitud de la endemia, desde el propio Instituto Provincial de Higiene se consideraba imprescindible el establecimiento en dicho centro de una sección de investigaciones microscópicas y trabajos experimentales centrados exclusivamente en el tracoma (IPHV, 1933). La información consultada no permite comprobar la materialización de este proyecto.

\section{El tracoma durante la Guerra Civil en la España republicana: escenario de aparición y reorganización antitracomatosa en Valencia}

Conviene destacar la presencia de dificultades metodológicas para el estudio de las enfermedades infecciosas durante la guerra por dos motivos. En primer lugar, el derrumbe de la estadística sanitaria diseñado por Marcelino Pascua, director general de Sanidad durante el primer bienio republicano, debido al estado de guerra (Barona Vilar, PerdigueroGil, 2008). Por tanto, los datos que se han conservados están incompletos y, además, debe tenerse en cuenta su posible sesgo propagandístico, tanto en la zona republicana como en el territorio insurgente. En cuanto a las fuentes locales, cabe destacar la ausencia total de documentación de archivo a partir del verano de 1937, coincidiendo con la incautación de los hospitales antitracomatosos de la ciudad de Valencia por parte del Estado republicano.

En la línea de lo que había hecho la Dirección General de Sanidad durante la etapa prebélica, a finales de 1937 el Ministerio de Instrucción Pública y Sanidad republicano editó un opúsculo en el que se glosaban los éxitos conseguidos en materia sanitaria tras siete meses de gobierno del Frente Popular, centrándose en las luchas antituberculosa y antitracomatosa, en las enfermedades mentales y en las infantiles. Pese a su posible carácter propagandístico, el folleto nos permite saber que la lucha antitracomatosa seguía figurando entre las prioridades de las autoridades sanitarias estatales. Según el ministerio, en mayo de 1937 existían cien camas destinadas a esa lucha en el Hospital de Madrid; en octubre de ese mismo año, el número de plazas había aumentado hasta las trescientas gracias a la entrada en funcionamiento del Internado Dermatológico de Campanar (Valencia), que posteriormente será analizado en profundidad. Asimismo, los responsables ministeriales aseguraban que en enero de 1938 las camas destinadas a la lucha antitracomatosa en la zona leal ascenderían a un total de ochocientas, dado que estaba previsto la habilitación de quinientas plazas más con la siguiente distribución: cien camas en el Hospital de Valencia; doscientas camas en la Colonia Fontanares (Valencia); cien unidades en el Hospital de Almería; y cien más en el de Albacete (Ministerio..., 1937).

Con respecto a la zona sublevada, tan solo tenemos noticia de que durante el primer trimestre de 1938 en las provincias y capitales de la España nacional se contabilizaron un total de 322 casos de tracoma (Vallejo de Simón, 1938a). De la zona republicana, unos autores afirmaban que "la zona roja española tampoco ha sido castigada seriamente 
por enfermedades infecto contagiosas y mucho menos por las de carácter pestilencial" (Anguera, 1938, p.42), mientras que otras fuentes aseguraban que "debido al estado de hacinamiento en que se vive en la España roja, y la falta de aislamiento de sus enfermos, la colocan en óptimas circunstancias favorables para su diseminación y propagación" (Vallejo de Simón, 1938b, p.46). Esta aparente incoherencia podría ser interpretada como un uso propagandístico de la salud pública por parte de los sublevados.

Los expertos de la Sociedad de Naciones realizaron una visita de inspección a la España republicana al inicio de 1937. Posteriormente, redactaron un informe en el que identificaban los cuatro principales problemas de salud pública: el tifus exantemático, la fiebre tifoidea, la varicela y la disentería (Rapport..., 1937). Los especialistas internacionales, por tanto, no consideraron que el tracoma supusiera una amenaza para la población en aquellos momentos. La estadística del Hospital Nacional de Enfermedades Infecciosas de Madrid, correspondiente al período comprendido entre el 19 de julio de 1936 y el 1 de enero de 1937, tampoco recogía ningún caso de tracoma. La situación epidemiológica de principios de 1937 en la España republicana sorprendió a los expertos de la Sociedad de Naciones, ya que durante los primeros meses de la contienda la salud de la población apenas se había deteriorado y no se habían producidos brotes epidémicos de grandes proporciones. El empeoramiento sanitario de la población se inició a finales de 1937 y se reflejó en un aumento de muertes por enfermedades endémicas como la tuberculosis y la fiebre tifoidea (Barona Vilar, Bernabeu-Mestre, 2008, p.262). Además, en diciembre de 1938 en algunas regiones de la España republicana el tracoma afectaba a más del 50\% de los niños (Mendlesohn, 2002, p.106). Pese a todo, los profundos problemas de salud que habían provocado tres años de guerra se agravaron aún más al finalizar el conflicto con la irrupción de epidemias de enfermedades características de las sociedades en crisis: tifus exantemático, viruela, fiebre tifoidea y difteria (Palanca, 1943).

Los problemas asociados al movimiento de refugiados se plantearon en la España republicana a finales de 1936, cuando la población evacuada se encontraba en torno al $14 \%$ de la población total del país y la saturación de los lugares receptores comenzaba a ser una realidad. La política del gobierno republicano consistía en trasladar a los refugiados a ciudades de retaguardia, como Valencia o Barcelona, siendo el contingente de niños el más numeroso (Barona Vilar, 2002, p.354).

En Barcelona las autoridades desarrollaron una política sanitaria especial para atender a los refugiados. Así, en Montjuïc se habilitó una estación sanitaria para identificar el problema de salud de los refugiados y poder derivarlos según su patología. Para los niños tuberculosos, escrofulosos y tracomatosos se instaló una residencia en el piso superior del Palau de Pedralbes y un sanatorio en el Guinardó (Hervàs Puyal, 2004).

La situación en Madrid respecto del tracoma era bien distinta. A principios de enero de 1937 el Instituto Nacional de Sanidad fue abandonado debido a la situación militar. Instalado provisionalmente en el Instituto Nacional de Terapéutica Experimental, el 20 de enero quedó habilitado en el antiguo local de la Escuela Nacional de Sanidad del paseo de Recoletos. Entre las actividades que allí se desarrollaban cabe destacar las investigaciones sobre el tracoma. Así, en los cinco primeros meses de 1937 disponían de 52 huevos de gallina inoculados y habían estudiado 1200 cortes histológicos. Los primeros resultados de estos 
trabajos fueron enviados a París para su publicación en la prestigiosa Revue Internationale du Trachome (Memoria-Resumen..., 1938, p.335).

Como ya ha sido señalado, la posición de retaguardia de Valencia durante la totalidad de la conflagración convirtió a la ciudad en un destino preferente para grandes contingentes de población civil evacuada (García Ferrandis, 2015). Efectivamente, a finales de 1936, la población refugiada en la España republicana superaba ya el millón de personas, 250 mil de las cuales habían sido acogidas en las provincias valencianas (Barona Vilar, 2002, p.354). Gran número de los refugiados acogidos en Valencia era población infantil que fue alojada en numerosas colonias (Fernández Soria, 1987; Alted, 2003; Escrivà, Maestre, 2011).

Este marcado crecimiento poblacional, al producirse en un corto periodo de tiempo y no corresponderse con un incremento de las infraestructuras urbanas, provocó el hacinamiento de gran parte de la población en condiciones infrahumanas, lo que desde finales de 1937 disparó las cifras de mendigos y vagabundos en las calles de la ciudad (Actas..., 1937, p.563). Además, durante la guerra las carencias alimentarias se agudizaron entre la población de la ciudad de Valencia (autóctona y refugiada), dado que la zona occidental, en manos de los rebeldes, era tierra de pasto, productora de carne y leche, lo que condicionó que gran parte de la población de Valencia padeciera un bajo aporte calórico, una escasez de proteínas de origen animal y una deficiencia de calcio y diversas vitaminas (Barona Vilar, 2006, p.28).

Así pues, todo parece indicar que en Valencia durante la Guerra Civil confluyeron los principales factores determinantes de la irrupción de una epidemia de tracoma, sin olvidar que la ciudad y la provincia tradicionalmente habían sido un foco endémico. Las siguientes palabras del director del Hospital Provincial apuntan en esa dirección: "Dado el carácter de extensión del tracoma en esta región litoral mediterránea, existe un gran contingente de enfermos tracomatosos que acuden a la consulta de oftalmología de este Hospital Provincial, contingente que las circunstancias actuales ha aumentado notablemente con la evacuación sobre Valencia de gran número de habitantes de otras zonas españolas" (Oficio..., 27 ago. 1937).

Otro testimonio del aumento de tracomatosos en la ciudad, como consecuencia de la llegada de refugiados, es el de Vicente Pérez Lorenzo (1903-1950), oftalmólogo del Hospital Provincial de Valencia y del dispensario antitracomatoso del Instituto Provincial de Higiene. Pérez Lorenzo trató a un matrimonio evacuado de Madrid y a sus cinco hijos, todos ellos enfermos de tracoma.

La evolución política que experimentó la España republicana afectó, como no podía ser de otra manera, a la esfera sanitaria. Pocos días después tras la insurrección militar, en Valencia quedó constituido el Comité Sanitario Popular (CSP), un organismo revolucionario que gestionó la política sanitaria valenciana durante los primeros meses. El CSP tuvo como prioridad el aumento de la oferta sanitaria de Valencia, consciente de que la posición geoestratégica de la ciudad la llenaría de heridos, enfermos y refugiados en poco tiempo. Tras la etapa revolucionaria y coincidiendo con el traslado del Gobierno a Valencia (noviembre de 1936), las autoridades republicanas impulsaron un proyecto político centralizador conscientes de que la fragmentación política era incompatible con la victoria. En Valencia, esta reestructuración política supuso, por una parte, la desaparición del CSP y la creación 
de las consejerías de Sanidad y de Asistencia Social, dentro del organigrama del Consejo Provincial de Valencia, un organismo pro-estatal (Gaceta..., 25 dic. 1936, p.1102). Por otra parte, en este contexto político centralista, el decreto de 12 de junio de 1937 dispuso que todos los hospitales cuyo déficit económico repercutiera en la calidad asistencial quedaran bajo el control técnico y administrativo del Ministerio Instrucción Pública y Sanidad (Gaceta..., 13 jun. 1937, p.597).

Durante su estancia en Valencia, el recién creado Ministerio de Sanidad y Asistencia Social editó un cartel en el contexto de la lucha contra el tracoma. ${ }^{6}$ Manuel Monleón (1904-1976) no dudó en relacionar la viruela y el tracoma con una serie de factores sociales (pobreza, incultura, trabajo en fábricas). En el cartel se puede observar perfectamente una blefaro-conjuntivitis granulosa de origen tracomatosa.

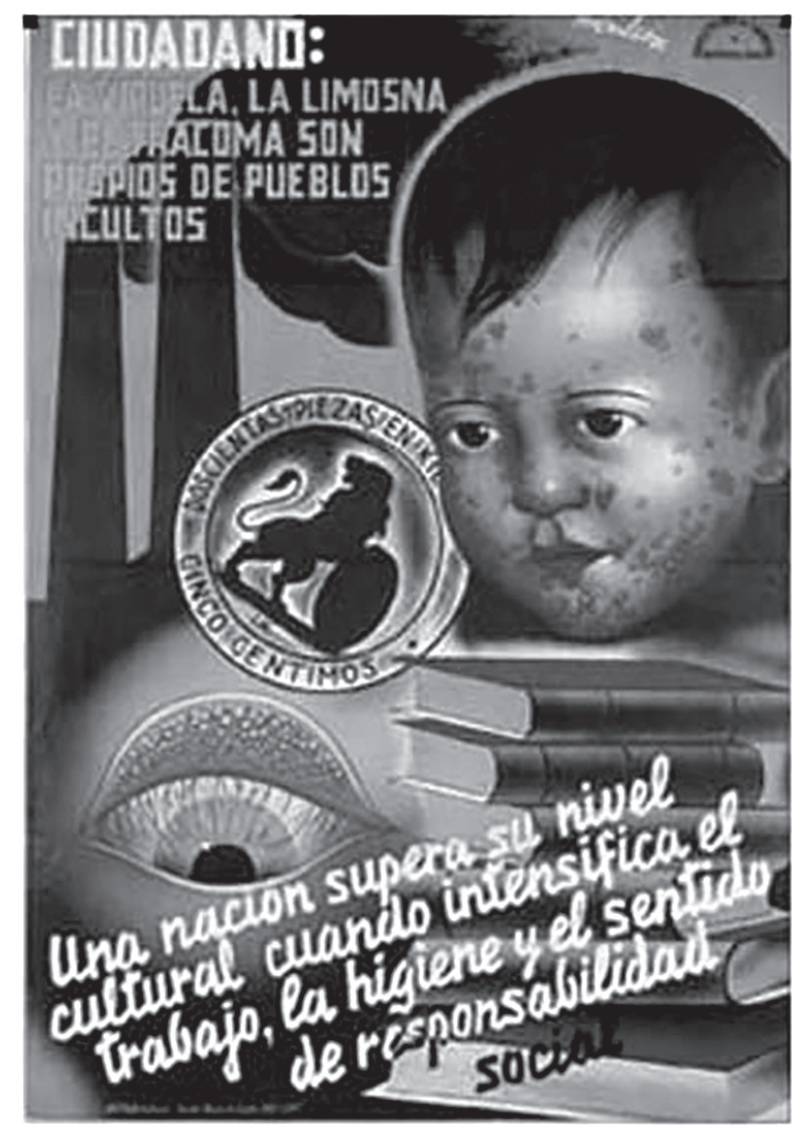

Figura 4: Cartel de la Guerra Civil, de Manuel Monleón, ca. 1936 (Biblioteca Histórica/Universitat de València)

Conviene recordar que, durante esta primera época, el ministerio estuvo dirigido por la anarquista Federica Montseny (1905-1994) y, al frente de la subsecretaria, situó a la pediatra socialista Mercedes Maestre (1904-1989). Durante un breve pero intenso período de dos meses, Maestre organizó las evacuaciones de población infantil y gestionó su asistencia socio-sanitaria. 
A continuación analizaremos cómo se reorganizó la lucha contra el tracoma infantil en Valencia durante la Guerra Civil que cristalizó fundamentalmente en la habilitación de tres hospitales infantiles. Por habernos referido anteriormente a ello, no tendremos en cuenta aquellas infraestructuras sanitarias que ya existían antes de la guerra y que sufrieron un aumento de la presión asistencial, es decir, el Hospital Provincial y el Instituto Provincial de Higiene.

\section{El Hospital Infantil Antitracomatoso de Alaquàs}

Es poca la información que nos ha llegado de este centro sanitario. Sabemos que empezó a funcionar en octubre de 1936, en la localidad de Alaquàs, muy cercana a Valencia (Nombramiento..., 10 oct.1936), pero desconocemos con exactitud el edificio que albergó el centro sanitario. Podría tratarse de la casa de ejercicios espirituales La Purisíma, incautada al estallar la guerra. Esta hipótesis resulta verosímil, ya que en agosto de 1936 el comité local se incautó de este edificio religioso y lo ofreció al CSP con la intención de instalar un hospital (Oficio..., 6 nov. 1936).

Luis Sabater Fornés (1897-1989) - inspector municipal de sanidad de Alaquàs - era el director médico del hospital. Además, entre el personal había un maestro. En marzo de 1937, Sabater hizo una solicitud muy detallada de material terapéutico en la que se incluía abundante instrumental quirúrgico común (bisturís, tijeras y pinzas) y material quirúrgico de uso oftalmológico específico, como separadores palpebrales de Desmarres (Oficio..., 1937). Este material parece revelar que en el hospital de Alaquàs el tracoma se trató quirúrgicamente.

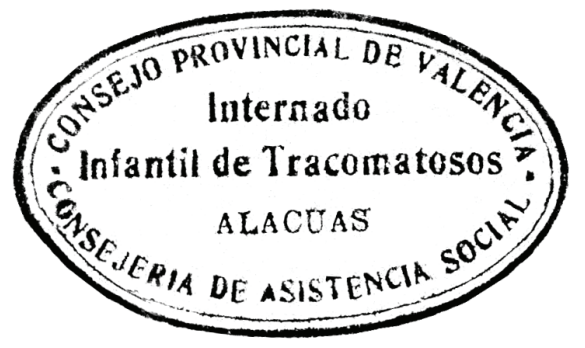

Figura 5: El Hospital de Alaquàs estuvo gestionado por la Consejería de Asistencia Social (Petición..., 1937)

A lo largo de la primavera de 1937, los niños ingresados en este hospital fueron trasladados progresivamente al hospital de Campanar (ver la próxima sección, debido a que de este hospital se habla en profundidad en el siguiente apartado, titulado El Hospital Infantil Antitracomatoso de Campanar). El proceso de centralización sanitaria iniciado por el gobierno republicano desde comienzos de 1937 podría estar detrás de este movimiento. Una vez clausurado el hospital, entre julio de 1937 y julio de 1938, el edificio fue utilizado como cárcel de mujeres emparentadas con los principales dirigentes insurgentes, como Pilar Millán Astray, Rosario Queipo de Llano, Pilar Jaraiz Franco y Carmen Primo de Rivera. ${ }^{7}$ La 
trayectoria efímera del hospital de Alaquàs justificaría el hecho de que nos hayan llegado tan pocas noticias de este centro sanitario.

\section{El Hospital Infantil Antitracomatoso de Campanar}

A finales de 1936, cuando numerosos niños ya habían sido evacuados a Valencia y provincia, el CSP decidió "establecer instituciones de carácter educativo para niños difíciles, problema que se le ha planteado en las distintas colonias de niños evacuados" (Delegación..., dic. 1936). Para llevar a cabo esta centralización eligieron las instalaciones del Patronato de la Juventud Obrera, en el barrio de Campanar. ${ }^{8}$ Sin embargo, lo que allí realmente se instaló a principios de 1937 fue un hospital infantil antitracomatoso (García Ferrandis, 2015). Nuestra hipótesis es que, al reunir a los "niños difíciles" de las numerosas colonias habilitadas, ${ }^{9}$ las autoridades se dieron cuenta de que muchos estaban afectados por el tracoma y decidieron dotar a la colonia de material médico y de instrumental quirúrgico, habilitando en realidad un hospital infantil antitracomatoso. Se pondría así en evidencia el carácter social del tracoma a través del triángulo niño difícil-niño pobreniño tracomatoso. Las siguientes palabras de Luís Sabater, director del hospital, parecen reforzar nuestra idea apuntando con claridad al origen social de la enfermedad: "En el primer período de la guerra se puso de manifiesto las lacras sociales que había en una sociedad llena de privilegios: niños abandonados; asilos en donde los niños, malnutridos vivían sin higiene" (Carta..., 19 mayo 1937).

Según el director, en estos asilos, gestionados en su mayor parte por la Iglesia, había niños internados casi ciegos a causa del tracoma. En las condiciones descritas no es de extrañar que el tracoma presentara tradicionalmente una elevada incidencia en los asilos infantiles de la ciudad. Así parece indicarlo el hecho de que entre el cuadro facultativo que prestaba sus servicios en uno de esos asilos, el de San Juan Bautista, en los momentos inmediatamente anteriores a la guerra figurara un "médico oculista, D. Eduardo Wieden" (Oficio..., 1 jun. 1936). Este es el contexto en el que se habilitó el hospital de Campanar. Sin embargo, unos meses más tarde, las condiciones de los asilos de la ciudad, que habían experimentado el preceptivo cambio de denominación, no habían mejorado sustancialmente. Así, sabemos que el 22 de septiembre de 1937 en el Instituto de Asistencia Social Gabriela Mistral (antigua Casa de Misericordia) estaban asilados un total de 38 enfermos de tracoma, de los cuales muchos eran niños procedentes del Orfanato Nacional de El Pardo, en Madrid (Relación..., 22 sep. 1937). Tenemos noticias de que de esta realidad se hicieron eco las voluntarias británicas Lydia Gee y Bronwen Williams, destacadas en Valencia por motivos humanitarios y que realizaron una visita de inspección a los asilos más importantes de la ciudad (Visita..., sep. 1937). ${ }^{10}$

Pese a todas las limitaciones, conviene señalar que para la Consejería de Sanidad valenciana la lucha antitracomatosa constituía una prioridad. Es lo que se desprende del análisis de la estructura y funcionamiento de su Departamento de Hospitales y Sanatorios, cuyos tres grandes ejes eran los centros médico quirúrgicos, los centros de atención psiquiátrica y los centros de lucha antituberculosa y antitracomatosa (Estructura..., jun. 1937). 


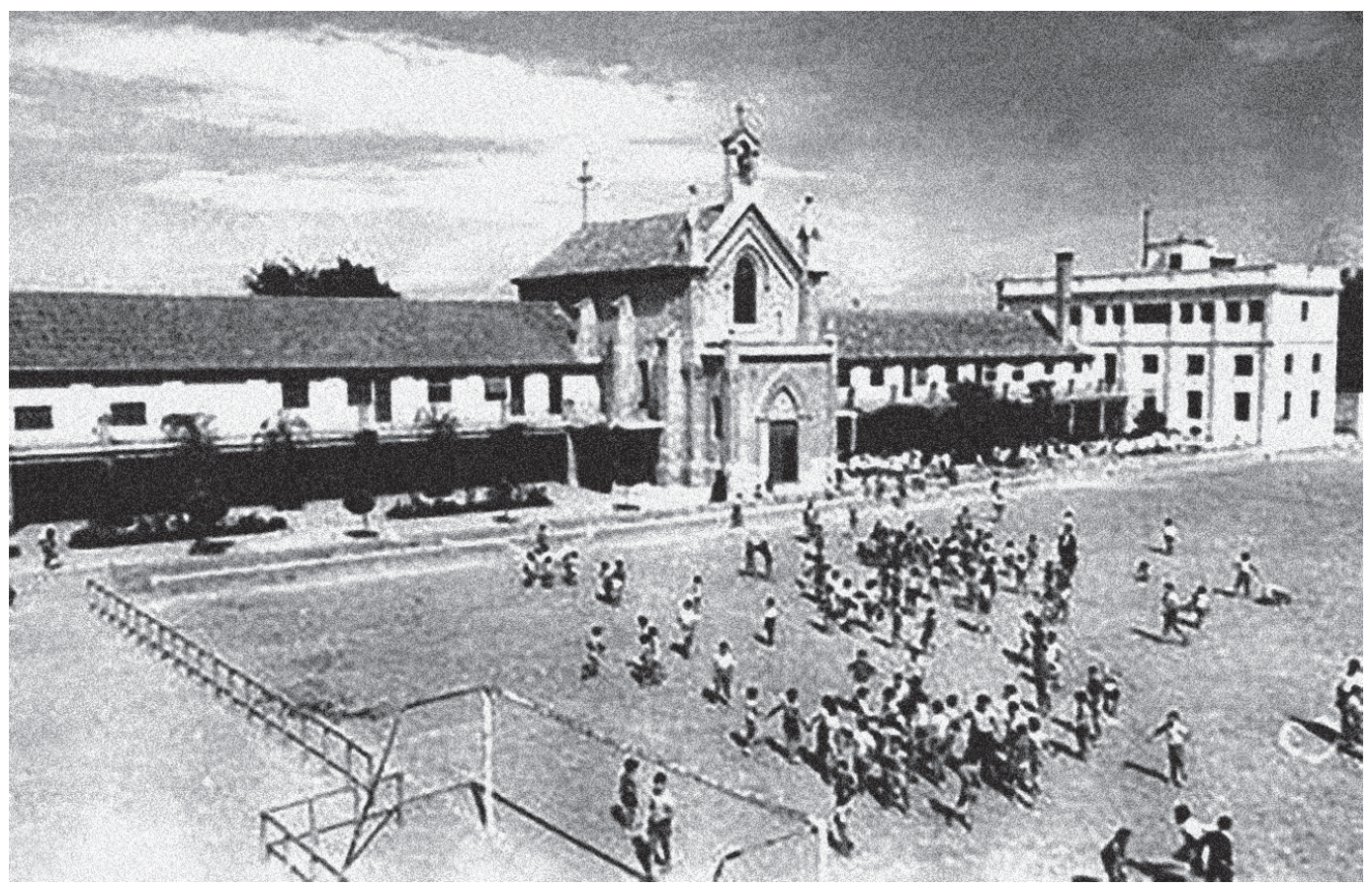

Figura 6: Instalaciones del Patronato de la Juventud Obrera en los años 1960 (Archivo personal de Don Eduard Pérez Lluch)

Además del director, el hospital de Campanar contaba con un practicante, tres enfermeras, cuatro maestros, personal auxiliar (limpieza, cocina etc.) y un guarda. Uno de los maestros era Félix Palenzuela, destinado en el Instituto Colonial Indígena de Santa Isabel (Fernando Póo) y a quien la sublevación militar le había sorprendido de vacaciones en Valencia (Oficio..., 9 ene. 1937). En mayo de 1937 el hospital acogía a 250 niños, aunque también dispensaba asistencia ambulatoria llegando, incluso, a proporcionar ropa limpia (Ropa..., 1937). En cuanto a la actividad sanitaria desarrollada, la documentación consultada revela que se abordó el tracoma desde el punto de vista quirúrgico, es decir, la extirpación de los gránulos tracomatosos de la conjuntiva y la cirugía palpebral para la corrección de formas retráctiles más graves: entropion, triquiasis y xerosis (Lista..., 1937). Por otra parte, hemos detectado un signo indirecto del carácter de refugiado de los niños, ya que entre los gastos hay 65 sellos "para las cartas que escriben a sus familiares los niños del Internado" (Facturas..., 1937). Además, sabemos que los niños y niñas mayores de 14 años realizaban pequeñas tareas por lo que recibían una pequeña gratificación semanal.

Siguiendo las recomendaciones de los salubristas de la época, los responsables del hospital eran conscientes de la gran importancia que tenía la educación básica de los niños dado la larga duración del tratamiento. Por este motivo, el director solicitó al ministro de Instrucción Pública y Sanidad la ampliación de la escuela y la creación de ocho plazas de maestros, argumentando que los niños necesitaban estar atendidos las 24 horas del día. El motivo de esta solicitud de ampliación era que el internado tenía a su cargo una gran cantidad de niños. Efectivamente, a principios de junio de 1937, el hospital daba cobijo a unos doscientos niños pese a que su capacidad era de cincuenta camas, lo que supuso el 
rechazo del ingreso de niños afectados por tracoma asilados en el Instituto Social Maestro Ripoll, la antigua Casa de Beneficencia (Oficio..., 7 jun. 1937). En este contexto, una visita de inspección efectuada el 3 de junio de 1937 por el consejero de Sanidad puso al descubierto las numerosas deficiencias que sufría el hospital. El hacinamiento obligaba a convivir a diferentes tipos de enfermos, lo que favorecía que al lado de niños afectados de un tracoma simple se encontraran otros con blefaritis complicada (García Ferrandis, 2015, p.163). En el informe también se consideraba inapropiado el local habilitado como escuela y se ponía de manifiesto que muchos de los pacientes también padecían tuberculosis, otra enfermedad de marcado carácter social; se denunciaba, asimismo, la falta de ropa y la deficiente alimentación de los niños ingresados (Visita..., 3 jun. 1937).

También existían problemas de índole burocrática. En este sentido, la Consejería de Sanidad consideraba que tanto la Consejería de Asistencia Social como el Ministerio de Sanidad y Asistencia Social tenían la obligación de cooperar económicamente en el sostenimiento de estos pacientes, dado que algunos de los niños procedían de los antiguos asilos de la ciudad y otros de zonas en guerra evacuadas. Finalmente, la falta de consenso hizo que el 16 de junio de 1937 la Consejería de Sanidad dejara de hacerse cargo del hospital de Campanar (Oficio..., 16 jun. 1937). Esta decisión unilateral surtió efecto de inmediato, de manera que a los dos días, ante una petición de la Consejería de Asistencia Social de ingreso en Campanar de una niña , la de Sanidad resolvió "que dicho internado no depende de nosotros" (Oficio..., 18 jun. 1937).

Finalmente, el deficiente estado del Hospital Infantil Antitracomatoso de Campanar fue el detonante para que el centro sanitario fuera incautado por el Ministerio de Instrucción Pública y Sanidad en el verano de 1937 en virtud del decreto de 12 de junio de ese año. En octubre de 1937, este hospital figura como el "Internado Dermatológico de Campanar", con capacidad para doscientas camas. Todo parece indicar, así pues, que el cambio de titularidad influyó positivamente en la capacidad asistencial del hospital y, eventualmente, en la atención médica que allí se dispensaba.

La última noticia que tenemos del hospital de Campanar se enmarca en la epidemia de tifus exantemático que asoló España durante la posguerra inmediata (García Ferrandis, Martínez-Vidal, 2019). Así, sabemos que las autoridades franquistas inyectaron cuatro millones de pesetas para el hospital de Campanar, "dedicado a la infancia abandonada" (Palanca, 1943, p.369). No debe perderse de vista, no obstante, el carácter propagandístico de la fuente, ya que se trata de la parte doctrinal del discurso del director general de Sanidad - José Alberto Palanca -, leído en la Real Academia de Medicina el 28 de febrero de 1943.

\section{El Hospital Dermatológico Infantil de Montcada}

Fue habilitado a principios de 1937 por el CSP como internado para dar acogida principalmente a niños refugiados afectados por sarna y tiña (Oficio..., 27 ene. 1937). Pese a no ser un hospital antitracomatoso en sí mismo, lo hemos incluido en este trabajo porque entre los ingresados había niños afectados por tracoma.

A finales de enero de 1937 estaba preparado para entrar en funcionamiento un hospital para milicianos en Montcada, localidad situada a escasos kilómetros al norte de Valencia 
bien comunicada por tren de cercanías. El encargado de poner en funcionamiento el hospital era Miguel Gil Palanca, médico de la vecina localidad de Carpesa (Boletín..., 1933, p.19). Finalmente, a principios de 1937, el edificio habilitado comenzó a funcionar como hospital infantil (Materiales..., 1937). Al igual que los de Alaquàs y Campanar, el Hospital Dermatológico Infantil de Montcada estaba dirigido por Luís Sabater. También contaba con cuatro maestros, dos guardadoras para los párvulos, una costurera y un vigilante nocturno (Nóminas..., 1937). El hacinamiento también fue un problema en el centro sanitario de Montcada: con capacidad para cien camas, llegó a acoger a 150 niños (Niños..., 3 jun. 1937).

En la gestión de este hospital igualmente se hizo patente la difícil delimitación de competencias entre las consejerías de Sanidad y de Asistencia Social. Por ejemplo, la solicitud de ingreso en el centro sanitario de una niña evacuada de Madrid fue cursada por la Consejería de Sanidad y autorizada por los responsables de la de Asistencia Social (Ingreso..., 8 abr. 1937). En cuanto a la dinámica de funcionamiento interno, los pacientes mayores de 12 años desempeñaban algunas tareas auxiliares recibiendo una pequeña gratificación. Además, había jóvenes conflictivos, enviados por el Tribunal de Menores, que realizaban tareas de carpintería con una remuneración de 150 pesetas mensuales. En la siguiente gráfica se puede apreciar la distribución según el lugar de procedencia de los 74 niños, de edades comprendidas entre los 2 y los 14 años, ingresados en el Hospital de Montcada el 3 de junio de 1937.

Gráfica 1: Procedencia de los niños ingresados en el Hospital Dermatológico Infantil de Montcada Tribunal Menores 2,70\%

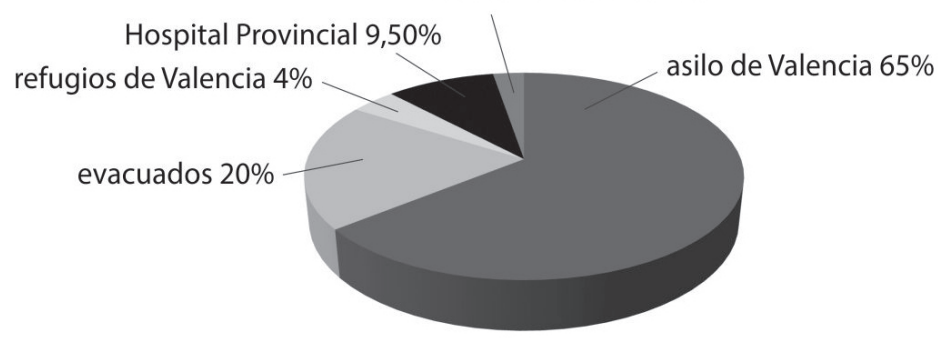

Fuente: elaboración propia a partir de datos consultados en el Arxiu General i Fotogràfic de la Diputació de València (D.6.1, caja 24, 1937).

La gran mayoría de los pacientes ingresados en el Hospital Dermatológico Infantil de Montcada eran niños procedentes de los diferentes asilos de la ciudad de Valencia. Esto no quiere decir que fueran niños valencianos: ya se ha señalado que, por ejemplo, los niños evacuados del Orfanato Nacional de El Pardo estaban acogidos en un asilo de la ciudad. En muchos otros casos los niños procedían directamente de zonas en conflicto y del Hospital Provincial de Valencia. Sin embargo, el lugar de procedencia más llamativo por su falta de salubridad son los refugios de la ciudad. Concebidos inicialmente como lugares seguros donde estar a salvo de los bombardeos, el colapso progresivo que sufrió la ciudad de Valencia 
al acoger a evacuados durante toda la guerra convirtió a estos lugares en infraviviendas donde se hacinaban familias en espacios oscuros, húmedos y mal ventilados.

Por otra parte, el material que los responsables del hospital solicitaban a la Consejería de Asistencia Social nos acercan al manejo de la sarna y de la tiña en aquella época. Así, en marzo de 1937, el administrador del centro solicitó 72 pastillas de jabón, algunos cepillos limpiamanos, desinfectantes (tintura de yodo, cloramina y agua oxigenada), material quirúrgico y de curas (compresas, vendas y gasas). Asimismo, se solicitó una gradilla y una pinza para tubos de ensayo y varias pipetas de cristal graduados, lo que nos permite inferir que el hospital de Montcada disponía de un pequeño laboratorio donde se realizan determinaciones hematológicas y bacteriológicas. También destaca la presencia de diverso material quirúrgico de uso oftalmológico, lo que parece confirmar que en este hospital se trató enfermos tracomatosos (Material..., 1937).

El 3 de junio de 1937, la misma comisión que inspeccionó el Hospital de Campanar visitó el de Montcada: "hemos observado el lamentable estado que tanto en el orden higiénico como en técnico-sanitario se encuentran..., los niños ingresados se encuentran desprovistos en absoluto de ropa" (Estado..., jun. 1937). El consejero atribuía esa situación al déficit económico que venía arrastrando el centro (Comunicación..., 27 ene. 1937). Por este motivo, y en virtud del decreto de 12 de junio de 1937, el Hospital Dermatológico Infantil de Montcada fue incautado a lo largo del verano de 1937 por el Ministerio de Sanidad y Asistencia Social.

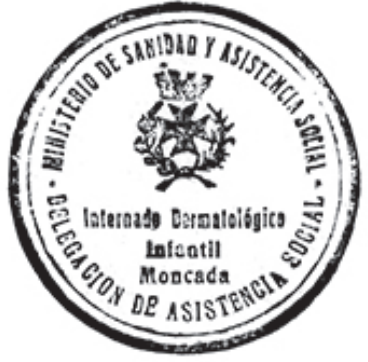

Figura 7: El Hospital de Montcada administrado por el Ministerio de Sanidad y Asistencia Social (Arxiu General i Fotogràfic de la Diputació de València, D.6.1, caja 24, 1937)

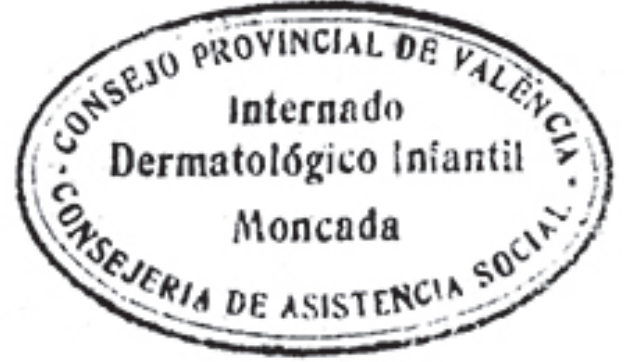

Figura 8: El Hospital de Montcada gestionado por la Consejería de Asistencia Social (Arxiu General i Fotogràfic de la Diputació de València, D.6.1, caja 24, 1937)

Antes de concluir, conviene señalar que, pese a los esfuerzos de las autoridades sanitarias en materia antitracomatosa, hemos localizado evidencias de que no fueron suficientes. Así, el 27 de agosto de 1937, la dirección del Hospital Provincial expuso al Consejo Provincial la necesidad de acometer una serie de medidas para mejorar la eficacia de la lucha contra el tracoma. Los responsables del Hospital Provincial propusieron la creación de una unidad específica para la lucha antitracomatosa dentro del mismo hospital y de un "consultorio para el tratamiento médico-quirúrgico ambulatorio del tracoma" en un local anexo a la consulta de oftalmología. Esta sección contaría con tres salas diferentes - para hombres, mujeres y niños - con una capacidad de entre cuatro y seis camas cada una (Oficio..., 27 ago. 1937). Nótese como estas propuestas de mejora - al igual que las medidas existentes 
- giraban alrededor de la vertiente asistencial del tracoma, sin tener en cuenta en ningún caso la vertiente preventiva y de diagnóstico precoz.

\section{Consideraciones finales}

Debido a la gran importancia geoestratégica de la ciudad de Valencia durante la totalidad de la contienda, aspiramos a que este trabajo trascienda su proyección local y se convierta en una aportación a la historiografía tanto de la Guerra Civil española, como de la medicina en épocas de conflicto. Hemos pretendido mostrar un estudio de casos que ayude a entender el manejo de una de las conocidas como "enfermedades de la miseria" en un escenario de crisis, como es la guerra.

Entre la abundante documentación consultada no se han encontrado referencias explícitas que apunten a la irrupción de una epidemia tracomatosa en Valencia durante la Guerra Civil, al menos durante el primer año de conflagración. A nuestro juicio, los motivos de esta falta de información convendría buscarlos en el derrumbe del sistema de recogida de datos epidemiológicos debido a las dificultades propias del estado de guerra y al uso propagandístico del control de las enfermedades infecciosas. No obstante, se han detectado evidencias que permitirían inferir que, efectivamente, el tracoma alcanzó proporciones epidémicas en Valencia durante el conflicto bélico. Consideramos que la más consistente sería la intensa reorganización de la lucha antitracomatosa que se acometió en la ciudad. Así, las autoridades sanitarias locales superaron la organización antitracomatosa promocionada por la Segunda República basada en la construcción de dispensarios, e improvisaron la habilitación de tres hospitales infantiles en la ciudad y sus alrededores. Sin embargo, esta readaptación no fue capaz de asumir el incremento progresivo de la demanda asistencial, lo que se tradujo en una degradación progresiva de las condiciones higiénicas de estos hospitales. El hacinamiento impidió la separación de los enfermos, aspecto fundamental en la vertiente profiláctica de la enfermedad, base, a su vez, de la lucha contra la enfermedad.

El origen social de la enfermedad tuvo varias consecuencias en diferentes ámbitos. En primer lugar, muchos de los niños eran pacientes pluripatológicos (tracoma, tuberculosis, escrófula, sarna y tiña). Se trata de enfermedades con una etiología y un tratamiento muy diferente pero que presentan un denominador común: la pobreza, es decir, su origen social. En segundo lugar, las complicadas relaciones entre las consejerías de Sanidad y de Asistencia Social debido a la dificultad en la delimitación de ambas competencias. En último lugar, la procedencia de los pacientes ingresados en los hospitales antitracomatosos valencianos refleja el origen social de la enfermedad: niños pobres y jóvenes conflictivos, la mayoría pertenecientes a familias desestructuradas a causa de la guerra. Por este motivo, los hospitales infantiles analizados asumieron otras funciones además de la terapéutica: la educación primaria, la formación profesional y la rehabilitación social. Este amplio espectro de actuación hizo que estos centros hospitalarios contaran con personal no sanitario: costureras, maestros, guardadoras de párvulos y vigilantes nocturnos.

Por otra parte, la presencia de abundante material quirúrgico en la documentación consultada revelaría que en los hospitales analizados el tracoma fue objeto de tratamiento quirúrgico. Parece razonable pensar, así pues, que en Valencia la guerra alteró la política 
sanitaria impulsada por la Segunda República basada en la prevención y en el diagnóstico precoz del tracoma, centrándose en la vertiente asistencial. Además, la contienda truncó el proyecto de establecer en Valencia un centro de investigaciones sobre el tracoma que, pese a la guerra, sí que funcionó con un alto nivel científico en Madrid, una ciudad que había acogido en 1933 un congreso internacional sobre la enfermedad. Las dinámicas sociales establecidas por los acontecimientos bélicos estarían detrás de esta diferencia. Así, en Madrid, aunque existían al menos cien camas hospitalarias reservadas a la lucha antitracomatosa, los espacios y recursos sanitarios se pudieron destinar en gran medida a la investigación, dado el gran contingente de población infantil que fue evacuado a lo largo de la guerra. En Valencia, en cambio, el gran número de enfermos tracomatosos reunidos - autóctonos y evacuados - obligó a las autoridades sanitarias a comportarse de manera pragmática, abandonando las vertientes científica y experimental del tracoma para centrarse en el ámbito asistencial, ya que, por otra parte, la prevención era difícil debido al hacinamiento de los pacientes.

\section{AGRADECIMIENTOS}

Este trabajo se enmarca en el proyecto de investigación financiado por el Ministerio de Ciencia, Innovación y Universidades del Gobierno de España "Acción médica humanitaria transnacional e innovación tecnológica en espacios de confinamiento (1870-1950)" (PID2019-104581GB-I00). El autor agradece a Àlvar MartínezVidal, por la revisión y mejora de la primera versión del texto y a Juan José Salazar Corral, profesor del Instituto de Investigaciones Oftalmológicas Ramón Castroviejo (Facultad de Medicina, Universidad Complutense de Madrid), por abrirme desinteresadamente las puertas de la biblioteca de dicho instituto.

\section{NOTAS}

${ }^{1}$ Uno de estos escenarios fue la inclusa del Hospital Provincial. Puede consultarse García Ferrandis, Martínez-Vidal (2016b, p.158).

${ }^{2}$ Conviene recordar que el tracoma es una queratoconjuntivitis contagiosa provocada por Chlamydia trachomatis. Fue una de las principales causa de ceguera en el pasado y en la actualidad provoca millones de casos en Asia, Oriente Medio y África (Karasch, 2008).

${ }^{3}$ Para ampliar información sobre la figura y trayectoria de Rubio Huerta, consúltese: Martínez-Vidal, Garcia Ferrandis (2017).

${ }^{4}$ Se utilizan imágenes correspondientes a Murcia porque no se ha encontrado ninguna para el caso de Valencia. Sin embargo, hemos considerado oportuno reproducirlas porque son representativas de la endemia tracomatosa que afectaba la costa mediterránea española.

${ }^{5}$ Lo que se reflejó en un potente aparato legislativo. Puede consultarse la Gaceta de Madrid (7 y 12 mayo 1936) y la Gaceta de la República (14 ene. 1937, 15 feb., 12 mayo, 21 mayo y 8 jul. 1938).

${ }^{6}$ Para saber más sobre el cartelismo durante la Guerra Civil, véase Castejón Bolea, Perdiguero Gil, Piqueras Fernández (2012).

${ }^{7}$ Para más información sobre esta prisión, véase Simó Rosaleny, Torres Fabra (2016). También puede verse el documental Cautivas, película de 2017 dirigida por Carmesina Franch.

${ }^{8}$ El Patronato de la Juventud Obrera era una institución benéfica vinculada a la Iglesia cuyo objetivo era formar profesionalmente a los jóvenes más desfavorecidos. En octubre de 1936, el padre Narciso Basté, director del Patronato, fue asesinado en el contexto de la ira anticlerical desatada en la zona republicana tras el fallido golpe de Estado.

${ }^{9}$ Para ampliar el concepto de "niño difícil" dentro de la encrucijada medicina, pedagogía y escuela, puede consultarse Del Cura González (2008).

${ }^{10}$ Ambas eran cuáqueras británicas (Mendlesohn, 2002, p.192). 


\section{REFERENCIAS}

ACTAS del Consejo Provincial de València, p.563 (Arxiu General i Fotogràfic de la Diputació de València, València). 1937.

ALTED, Alicia. Los niños de la Guerra Civil. Anales de Historia Contemporánea, v.19, p.43-58, 2003.

ÁLVAREZ, Ramón. Trabajos del Servicio Antitracomatoso. Revista de Sanidad e Higiene Pública, v.11, p.548-553, 1936.

ANGUERA, Antonio. Servicios sanitarios con motivo de la inmigración durante la guerra. Revista de Sanidad e Higiene Pública, v.1, n.25, p.42, 1938.

ARRIZABALAGA, Jon; MARTÍNEZ-VIDAL, Àlvar; PARDO TOMÁS, José. La salut en la història d'Europa. Barcelona: Publicacions de la Residència d'Investigadors, 1998.

BARONA VILAR, Carmen. Las políticas de la salud: la sanidad valenciana entre 1855 y 1936. València: Publicacions de la Universitat de València, 2006.

BARONA VILAR, Josep Lluís. La salud de la población según los informes internacionales, 1936-1940. Madrid: Sociedad Estatal de Conmemoraciones Culturales, 2006.

BARONA VILAR, Josep Lluís. Salud, enfermedad y muerte: la sociedad valenciana entre 1833 y 1939. València: Institució Alfons el Magnànim, 2002.

BARONA VILAR, Josep Lluís; BERNABEUMESTRE, Josep. La salud y el Estado: el movimiento sanitario internacional y la administración española, 1841-1945. València: Publicacions de la Universitat de València, 2008.

BARONA VILAR, Josep Lluís; PERDIGUERO-GIL, Enrique. Health and the war: changing schemes and health conditions during the Spanish Civil War. Dynamis, v.28, p.103-126, 2008.

BERNABEU-MESTRE, Josep; GALIANASÁNCHEZ, María Eugenia; CREMADES MONERRIS, Angela. Environment and health with respect to a poverty-related disease: the epidemiology of trachoma in Spain, 1925-1941. História, Ciências, Saúde - Manguinhos, v.20, n.2, p.1605-1619, 2013.

BOLETÍN de la Unión Sanitaria Valenciana, p.19, suplemento, 1933.

BROWNE, Sebastian. Medicine and conflict: the Spanish Civil War and its traumatic legacy. London: Routledge, 2018.

CARTA dirigida al ministro de Instrucción Pública y Sanidad. D.6.1, caja 13, Hospital Antitracomatoso de Campanar (Arxiu General i
Fotogràfic de la Diputació de València, València). 19 mayo 1937.

CASTEJÓN BOLEA, Ramón; PERDIGUERO GIL, Enrique; PIQUERAS FERNÁNDEZ, José Luis (ed.). Las imágenes de la salud: cartelismo sanitario en España, 1910-1950. Alicante, Madrid: Instituto Alicantino de Cultura Juan Gil-Albert, Consejo Superior de Investigaciones Científicas, 2012.

COMUNICACIÓN del director del Hospital de Niños de Moncada al ministro de Sanidad y Asistencia Social. D.6.1, c. 24 (Arxiu General i Fotogràfic de la Diputació de València, València). 27 ene. 1937.

CONCILIUM Ophtalmologicum, 14., 1933, Madrid. Actas... Madrid: Universidad Complutense de Madrid, 1933.

CONI, Nicholas. Medicine and warfare: Spain, 1936-1939. London: Routledge; Cañada Blanch Studies on Contemporary Spain, 2007.

COOTER, Roger; HARRISON, Mark; STURDY, Steve (ed.). War, medicine and modernity. Stroud: The History Press, 1999.

DEL CURA GONZÁLEZ, Mercedes. Medicina y pedagogía en la escuela: el discurso sobre la anormalidad infantil en la España del primer tercio del siglo XX. In: Martínez Pérez et al. (coord.). La gestión de la locura: conocimiento, prácticas y escenarios (España, siglos XIX-XX). Cuenca: Ediciones de la Universidad de CastillaLa Mancha, 2008. p.433-456.

DELEGACIÓN de Asistencia Social del Comité Sanitario Popular. D.6.1, caja 20 (Arxiu General i Fotogràfic de la Diputació de València, València). dic. 1936.

DGS, Dirección General de Sanidad. Servicio Antitracomatoso. Cartilla de profilaxis individual contra el tracoma. Madrid: Omnia, 1934.

DGS, Dirección General de Sanidad. La Sanidad en la República: dos años de gestión. Madrid: Imprenta Gráfica Universal, 14 abr. 1933.

DGS, Dirección General de Sanidad. Servicio Antitracomatoso. Memoria de los trabajos realizados por el Servicio Antitracomatoso durante el año 1932. Madrid: Ministerio de la Gobernación, 1933.

ESCRIVÀ, Cristina; MAESTRE, Rafel. De las negras bombas a las doradas naranjas: colonias escolares, 1936-1939. Tavernes Blanques: Eixam, 2011.

ESTADO de los hospitales Internado Dermatológico de Moncada y Antitracomatoso de Campanar. D.6.1, caja 13 (Arxiu General i 
Fotogràfic de la Diputació de València, València). jun. 1937.

ESTRUCTURA y funcionamiento del Departamento de Hospitales y Sanatorios de la Consejería de Sanidad. D.6.1, caja 17 (Arxiu General i Fotogràfic de la Diputació de València, València). jun. 1937.

FACTURAS del Hospital de Campanar. D.6.1, caja 13 (Arxiu General i Fotogràfic de la Diputació de València, València). 1937.

FERNÁNDEZ SORIA, Juan Manuel. La asistencia a la infancia en la Guerra Civil: las colonias escolares. Revista de Historia de la Educación, v.6, p.83-128, 1987.

GACETA de la República, 8 jul. 1938.

GACETA de la República, 21 mayo 1938.

GACETA de la República, 12 mayo 1938.

GACETA de la República, 15 feb. 1938.

GACETA de la República, p.597, 13 jun. 1937.

GACETA de la República, 14 ene. 1937.

GACETA de la República, p.1102, 25 dic. 1936.

GACETA de Madrid, 12 mayo 1936.

GACETA de Madrid, 7 mayo 1936.

GALIANA-SÁNCHEZ, María Eugenia; BERNABEU-MESTRE, Josep. Salud comunitaria y acción social en el control epidemiológico del tracoma infantil, España (1932-1939). Asclepio, v.63, n.2, p.507-520, 2011.

GALIANA-SÁNCHEZ, María Eugenia; CREMADES MONERRIS, Ángela; BERNABEUMESTRE, Josep. Sanitary campaigns against trachoma in Spain. In: Andersen, Astrid et al. (ed.). Making a new countryside: health policies and practises in European history, ca. 1860-1950. Berna: Peter Lang, 2010. p.101-111.

GARCÍA FERRANDIS, Xavier. L'assistència sanitària a la ciutat de València durant la Guerra Civil. València: Publicacions de la Universitat de València, 2015.

GARCÍA FERRANDIS, Xavier. Aspectos epidemiológico-asistenciales de la tuberculosis en València durante la Guerra Civil española y la posguerra inmediata, 1936-1941. Llull, v.36, n.77, p.13-34, 2013.

GARCÍA FERRANDIS, Xavier; MARTÍNEZVIDAL, Àlvar. Public health, urban space and social exclusion in postwar Spain: the exanthematic typhus epidemic in the city of València, 1941-1943. História, Ciências, Saúde Manguinhos, v.26, n.2, p.445-464, 2019.
GARCÍA FERRANDIS, Xavier; MARTÍNEZVIDAL, Àlvar. L'assistència hospitalària en un dels principals bastions republicans durant la Guerra Civil espanyola: la ciutat de València. Afers, v.84, p.379-380, 2016a.

GARCÍA FERRANDIS, Xavier; MARTÍNEZVIDAL, Àlvar. Límites de la asistencia médica y social durante la Guerra Civil española en una ciudad de retaguardia: la Inclusa del Hospital Provincial de València. Asclepio, v.68, n.2, p.158, 2016b.

GÓMEZ BRAVO, Gutmaro. Vida cotidiana en la zona republicana: días de hambre y miseria. $L a$ Aventura de la Historia, n.213, p.58-64, 2016.

GÓMEZ BRAVO, Gutmaro. Terror rojo, violencia revolucionaria, y el fin del mundo en la retaguardia republicana. Historia del Presente, n.19, p.155-162, 2012.

HERVÀS PUYAL, Carles. Sanitat a Catalunya durant la República i la Guerra Civil: política i organitzacions sanitàries: l'impacte del conflicte bèl-lic. Barcelona: Universitat Pompeu Fabra, 2004.

INGRESO en el Hospital de Moncada. D.6.1, caja 24. Hospital Dermatológico Infantil de Moncada (Arxiu General i Fotogràfic de la Diputació de València, València). 8 abr 1937.

IPHV, Instituto Provincial de Higiene de València. Inspección Provincial de Sanidad. Memoria de los servicios sanitarios provinciales, año 1933. València: Imprenta hijo de F. Vives Mora, 1933. p.148, 161.

JIMÉNEZ LUCENA, Isabel. El tifus exantemático de la posguerra española, 1939-1943: el uso de una enfermedad colectiva en la legitimación del "Nuevo Estado". Dynamis, v.14, p.185-198, 1994.

KARASCH, Mary. Ophtalhmia (conjunctivitis and trachoma.) In: Kiple, Kenneth (ed.). The Cambrigde world history of human disease. New York: Cambridge University Press, 2008. p.897906.

LISTA de material quirúrgico oftalmológico. D.6.1, caja 13, Hospital Antitracomatoso de Campanar (Arxiu General i Fotogràfic de la Diputació de València, València). 1937.

MARQUÉS, Pierre. La Croix Rouge pendant la Guerre Civil d'Espagne, 1936-1939:

les missionnaires de l'humanitaire. Paris: L'Harmattan, 2000.

MARTÍNEZ-VIDAL, Àlvar; GARCÍA FERRANDIS, Xavier. Medicina i valencianisme durant la Segona República: l'oftalmòleg Llorenç Rubio i Huerta i el IX Congrés de Metges i Biòlegs de Llengua Catalana (Perpinyà, 1936). In: 
Ferragud, Carmel (ed.). Biografies mèdiques, sanitat municipal, educació sanitària i epidèmies en la ribera del Xúquer durant el segle XX. València: Publicacions de la Universitat de València, 2017. p.69-80.

MATERIAL solicitado por el director médico del hospital de Moncada. D.6.1, caja 24, Hospital Dermatológico Infantil de Moncada (Arxiu General i Fotogràfic de la Diputació de València, València). 1937.

MATERIALES avalados por el director del Hospital Dermatológico Infantil Moncada. D.6.1, caja 24, Hospital Dermatológico Infantil de Moncada (Arxiu General i Fotogràfic de la Diputació de València, València). 1937.

MEDINA, Rosa María; RODRÍGUEZ-OCAÑA, Esteban. Profesionalización médica y campañas sanitarias: un proceso convergente en la medicina española del primer tercio del siglo XX. Dynamis, v.14, p.77-94, 1994.

MELIS, Paola M; POZZI, Lucia. Una malattia della povertà: il tracoma infantile in Sardegna. In: Breschi, Marco; Pozzi, Lucia (dir.). Mortalità e stato di salute dalla nascita alla prima adolescenza: indagini micro in Italia, secoli $X I X-X X$. Udine: Forum, 2013. p.157-187.

MEMORIA-resumen de los trabajos del Instituto Nacional de Sanidad desde el 1 de enero hasta 31 de mayo de 1937. Revista de Sanidad e Higiene Pública, v.5, p.335, 1938.

MENDLESOHN, Farah. Quaker relief work in the Spanish Civil War. Lewiston/Lampeter: The Edwin Mellen Press, 2002. p.106.

MINISTERIO de Instrucción Pública y Sanidad. Hacia una nueva asistencia médica del pueblo: 7 meses de labor del Gobierno del Frente Popular. Madrid: Ministerio de Instrucción Pública y Sanidad, 1937. p.26- 27.

MOLERO MESA, Jorge. Malaltia, classe obrera i revolució a l'Espanya del primer terç del segle XX. In: Pardo Tomás, José; Martínez-Vidal, Àlvar (coord.). Salut i societat a les portes del segle XXI: Memorial Félix Martí Ibañez (19111972). Barcelona: Publicacions de la Residència d'Investigadors, 2006. p.29-53.

MOLERO MESA, Jorge. Enfermedad y previsión social en España durante el primer franquismo (1936-1951). El frustrado seguro obligatorio contra la tuberculosis. Dynamis, v.14, p.199-225, 1994.

MOLERO MESA, Jorge. La tuberculosis como enfermedad social en los estudios epidemiológicos anteriores a la Guerra Civil. Dynamis, v.9, p.185-224, 1989.
NIÑOS existentes en el Hospital de Moncada. D.6.1, caja 24. Hospital Dermatológico Infantil de Moncada (Arxiu General i Fotogràfic de la Diputació de València, València). 3 jun. 1937.

NOMBRAMIENTO de una practicante para el Internado de niños tracomatosos de Alacuás. D.6.1, caja 28 (Arxiu General i Fotogràfic de la Diputació de València, València). 10 oct. 1936.

NÓMINAS del personal. D.6.1, caja 24, Hospital Dermatológico Infantil de Moncada (Arxiu General i Fotogràfic de la Diputació de València, València). 1937.

OFICIO de la Consejería de Asistencia Social al director general de Marruecos y colonias. D.6.1, caja 20 (Arxiu General i Fotogràfic de la Diputació de València, València). 9 ene. 1937.

OFICIO de la Consejería de Sanidad a la Consejería de Asistencia Social. D.6.1, caja 16 (Arxiu General i Fotogràfic de la Diputació de València, València). 18 jun. 1937.

OFICIO de la Consejería de Sanidad a la Consejería de Asistencia Social. D.6.1, caja 16 (Arxiu General i Fotogràfic de la Diputació de València, València). 16 jun. 1937.

OFICIO del Comité Sanitario Popular de València al Comité Ejecutivo Popular de Alacuás. D.6.1, caja 16 (Arxiu General i Fotogràfic de la Diputació de València, València). 6 nov. 1936.

OFICIO del Departamento de Hospitales al consejero de Asistencia Social. D.6.1 c.13, Hospital Antitracomatoso de Campanar (Arxiu General i Fotogràfic de la Diputació de València, València). 7 jun. 1937.

OFICIO del director del Asilo de San Juan Bautista al secretario del Colegio Oficial de Médicos de València (Archivo de la Fundación San Juan Bautista, València). 1 jun. 1936.

OFICIO del director del Hospital de Niños de Moncada al ministro de Sanidad y Asistencia Social. D.6.1, caja 24 (Arxiu General i Fotogràfic de la Diputació de València, València). 27 ene. 1937.

OFICIO del director del Hospital Provincial de València al Consejo Provincial. I-2.4, caja 8, legajo 32 (Arxiu General i Fotogràfic de la Diputació de València, València). 27 ago. 1937.

OFICIO de Luis Sabater a Juan Murria. D.6.1, caja 13, Hospital Antitracomatoso de Campanar (Arxiu General i Fotogràfic de la Diputació de València, València). 1937.

PALANCA, José Alberto. Las epidemias de la postguerra. Semana Médica Española: Revista 
Técnica y Profesional de las Ciencias Médicas, v.7, n.1, p.359-375, 1943.

PALFREEMAN, Linda. Spain bleeds: the development of battlefield blood transfusion during the Civil War. Chicago: Sussex Academic Press, 2015.

PETICIÓN de material para el Hospital de Alaquàs. D.6.1, caja 13, Hospital Antitracomatoso de Campanar (Arxiu General i Fotogràfic de la Diputació de València, València). 1937.

POZZI, Lucia; BERNABEU-MESTRE, Josep; GALIANA-SÁNCHEZ, María Eugenia. Le modèle explicatif des maladies infectieuses associées à la misère et à la pauvreté: l'expérience espagnole et italienne dans la première moitié du XXe siècle. Histoire, Économie et Société, v.36, p.39-56, 2017.

POZZI, Lucia; GALIANA-SÁNCHEZ, María Eugenia; BERNABEU-MESTRE, Josep. La cooperación internacional en la lucha contra el tracoma: el papel de la Sociedad de Naciones, 1923-1935. In: Barona, Josep Lluís; GuillemLlobat, Ximo (dir.). Sanidad internacional y transferencia del conocimiento científico: Europa, 1900-1975. València: Publicacions de la Universitat de València, 2015. p.45-66.

RAPPORT sur la misión sanitaire en Espagne (28 déc. 1936-15 jan. 1937). Revista de Sanidade Higiene Pública, v.12, n.5, p.297-332, 1937.

RELACIÓN nominal de enfermos afectos de tracoma. D.6.1, caja 30. Instituto de Asistencia Social Gabriela Mistral (Arxiu General i Fotogràfic de la Diputació de València, València). 22 sep. 1937.

RODRÍGUEZ OCAÑA, Esteban. El informe sobre la sanidad española (1926) de Charles A. Bailey, enviado de la Fundación Rockefeller. Cronos, v.4, n.1-2, p.63-79, 2001.

RODRÍGUEZ OCAÑA, Esteban et al. La acción médico-social contra el paludismo en la España metropolitana y colonial del siglo XX. Madrid: Consejo Superior de Investigaciones Científicas, 2003.
ROPA necesaria en el hospital de Campanar. D.6.1, caja 13, Hospital Antitracomatoso de Campanar (Arxiu General i Fotogràfic de la Diputació de València, València). 1937.

RUBIO HUERTA, Lorenzo. El problema social del tracoma: el tracoma y la escuela. Boletín del Instituto de Higiene de la Provincia de València, v.71, p.2-4, 1933.

SIMÓ ROSALENY, Antoni; TORRES FABRA, Ricard Camil. La violència política contra les dones (1936-1953): el cas de la privació de llibertat a la província de València. València: Institució Alfons el Magnànim, 2016.

SOCÍAS, Arnaldo. Estudio de la distribución de la incidencia y de los factores epidemiológicos del tracoma en España, con un resumen de la distribución de la primera en todo el ecúmene. Revista de Sanidad e Higiene Pública, n.5, p.371403, 1942.

STEINACHER, Gerald. Humanitarians at War: the Red Cross in the shadow of the Holocaust. New York: Oxford University Press, 2017.

VALLEJO DE SIMÓN, Vicente. Estudio estadístico sanitario del primer trimestre del año actual (1938). Revista de Sanidad e Higiene Pública, v.13, n.3, p.165-185, 1938a.

VALLEJO DE SIMÓN, Vicente. Notas estadísticas del Primer Año Triunfal. Revista de Sanidad e Higiene Pública, v.1, n.43, p.46, 1938b.

VISITA de inspección. D.6.1, caja 13, Hospital Antitracomatoso de Campanar (Arxiu General i Fotogràfic de la Diputació de València, València). 3 jun. 1937.

VISITA de Lydia Gee y Bronwen L. Williams al Instituto de Asistencia Social Maestro Ripoll. D.6.1, caja 20 (Arxiu General i Fotogràfic de la Diputació de València, València). sep. 1937.

WILLIS, Elizabeth A. Medical responses to civil war and revolution in Spain, 19361939: international aid and local selforganization. Medicine, Conflict and Survival, v.24, n.3, p.159-173, 2008.

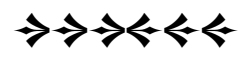

